\title{
O USO DE TEXTOS DE DIVULGAÇAO CIENTÍFICA PARA O ENSINO DE CONCEITOS SOBRE ECOLOGIA A ESTUDANTES DA EDUCAÇÃO BÁSICA
}

\section{The use of scientific popularization texts for teaching concepts about Ecology to basic education' students}

\author{
André Perticarrari ${ }^{1}$ \\ Fernando Rossi Trigo ${ }^{2}$ \\ Marisa Ramos Barbieri ${ }^{3}$ \\ Dimas Tadeu Covas ${ }^{4}$
}

\begin{abstract}
Resumo: O objetivo desta pesquisa foi avaliar o processo de aprendizagem de alunos do Ensino Básico a partir do uso de texto de divulgação científica desenvolvido pela Casa da Ciência do Hemocentro de Ribeirão Preto, com participação de pesquisadores. A prática pedagógica foi baseada em estudo de texto como técnica de ensino e consistiu na leitura, estudo e discussão do texto sobre Ecologia chamado "Lago e floresta: tão diferentes, mas muito semelhantes", o qual abordava o funcionamento dos ecossistemas. Foram aplicados questionários para avaliação da articulação de conceitos apresentada pelos alunos, cujas respostas foram analisadas de acordo com os objetivos cognitivos de Bloom. Com os resultados obtidos, pode-se afirmar que o uso de texto adequadamente preparado, associado à ação do professor como mediador, interferindo no processo cognitivo, e do aluno como agente ativo, possibilitou que os alunos fossem além do conhecimento de terminologias e fatos, importantes para a aprendizagem significativa.
\end{abstract}

Palavras-chave: Ensino de Ciências. Ensino-aprendizagem. Divulgação científica. Difusão do conhecimento.

\begin{abstract}
The aim of this research was to evaluate the learning process among students through the use of science popularization texts on Ecology developed by the 'House of Science' of the Ribeirão Preto's Hemocenter, with participation of their researchers. The pedagogical practice was based on the reading of a text as a study technique and constituted of the reading, study and discussion of a text on Ecology named "Lake and forest: so different, but very similar" which based on the ecosystem working. Data were collected through questionnaires and the students' answers were analyzed according to the cognitive objectives proposed by Bloom. The results showed that the use of a text properly prepared, associated to teacher's action, as mediator, and the student as an active agent, were important for a significant learning.
\end{abstract}

Keywords: Science education. Ecology education. Popularization of science. Knowledge diffusion.

\footnotetext{
${ }^{1}$ Licenciado e Bacharel em Ciências Biológicas, doutor em Ciências. Docente, Casa da Ciência do Hemocentro de. Ribeirão Preto. Ribeirão Preto, SP, Brasil.<aperticarrari@hotmail.com>

${ }^{2}$ Licenciado e Bacharel em Ciências Biológicas. Docente, Casa da Ciência do Hemocentro de Ribeirão Preto.

Ribeirão Preto, SP, Brasil. <fernando_r_trigo@yahoo.com.br>

${ }^{3}$ Graduada em História Natural, doutora em Filosofia. Coordenadora, Casa da Ciência do Hemocentro de Ribeirão Preto. Ribeirão Preto, SP, Brasil.<marisa@hemocentro.fmrp.usp.br>

${ }^{4}$ Graduado e doutor em Medicina. Diretor, Hemocentro de Ribeirão Preto. Ribeirão Preto, SP, Brasil.

<dimas@fmrp.usp.br>

${ }^{1}$ Casa da Ciência, Hemocentro de Ribeirão Preto

Rua Tenente Catão Roxo, 2501

Campus Universitário - Monte Alegre,

Ribeirão Preto, SP

369

$14.051-140$

Ciência छ̊̀ Educação, v. 16, n. 2, p. 369-386, 2010
} 
Perticarrari, A. et al.

\section{Introdução}

A pesquisa é parte integrante e base do processo de ensino-aprendizagem quando professores propõem a busca de informações em fontes diversas, que complementam discussões propostas em sala de aula (DEMO, 1984, 1996). Uma boa aprendizagem envolve a participação direta do estudante, onde ele é o sujeito ativo de seu processo de aprendizagem, construindo e reconstruindo o próprio conhecimento (PIAGET, 1977; DRIVER, 1989; OLIVEIRA, 1993; PERTICARRARI et al., 2007).

Uma das fontes que pode ser utilizada por professores são os textos de divulgação científica. Estudos sugerem que a contribuição da divulgação científica para o ensino pode se efetivar em potenciais benefícios, advindos do contato com diferentes formas de dizer e argumentar, presentes nestes textos, e por meio da discussão de temas recentes relacionados ao desenvolvimento da ciência, trazendo informações contextualizadas e atuais (MARTINS, NASCIMENTO e ABREU, 2004).

$\mathrm{Na}$ escola, os principais textos utilizados no ensino de ciências são aqueles presentes nos livros didáticos, que trazem uma visão fragmentada e desarticulada (GAMBARINI e BASTOS, 2006) em praticamente todas as áreas do conhecimento. No ensino de Ecologia não é diferente. Porém, os conceitos não podem ser vistos de forma fragmentada, ou seja, o ambiente não é fragmentado e todos os componentes de um ecossistema interagem entre si de maneira complexa. Para aprender ecologia se exige, além do entendimento dos conceitos isolados, a articulação entre eles para se entenderem as interações entre os seres vivos e o ambiente e o funcionamento dos diversos ecossistemas do planeta. Contudo, cabe ao professor promover a articulação dos diferentes conceitos, conduzindo os alunos a perceberem as relações entre os diferentes fenômenos. Neste contexto, é fundamental destacar o papel do professor como agente ativo no processo educacional, uma vez que seu trabalho vai além do simples ato de ministrar aulas, passando a agir como um orientador dos alunos (CARVALHO e GILPÉREZ, 1993).

\section{Casa da Ciência e a difusão e divulgação do conhecimento}

A Casa da Ciência - que faz parte do projeto educacional "As células, o genoma e você", do Centro de Terapia Celular do Hemocentro de Ribeirão Preto, um do dez Cepids (Centro de Pesquisa Inovação e Difusão) apoiados pela Fapesp, desde 2001 - procura, em seus projetos e programas, desenvolvidos com alunos e professores, provocar articulações entre conceitos científicos. Nos processos de ensino-aprendizagem e difusão de conceitos científicos desenvolvidos com pesquisadores, professores e alunos, acredita-se que a memória escrita passa a facilitar o caminho para os grupos de alunos e professores que se sucedem nos diversos programas e, assim, pode ser possível iniciar uma rede de comunicação que sustente uma cultura científica nas escolas.

Além disso, conta com uma casa no Campus da USP de Ribeirão Preto - O MuLEC (Museu e Laboratório de Ensino de Ciências), montado com apoio da Fundação Vitae (2005) - que abriga um acervo de materiais (maquetes, esculturas, fotos, textos, desenhos, painéis, carpoteca, coleção de fósseis e de zoologia) resultantes de trabalhos desenvolvidos por alunos 
e professores no Laboratório de Ensino de Ciências da Faculdade de Filosofia, Ciências e Letras de Ribeirão Preto/USP (LEC), no período de 1981 a 1999, e por programas educacionais atuais. Este espaço constitui um local de exposição permanente, voltado para a difusão e divulgação dos resultados alcançados nos mais de vinte anos de trabalho de pesquisa em educação, desenvolvidos pelo LEC e, atualmente, pela Casa da Ciência.

Para divulgar saberes produzidos no ambiente da USP e do Hemocentro de Ribeirão, abordando temas desenvolvidos em formatos diversos, diferentes dos abordados nos livros didáticos, desenvolveu-se o projeto "Folhetins: Material de Divulgação Científica do MuLEC", com apoio do Fundo de Cultura e Extensão Universitária da USP. A elaboração dos folhetins tem sido fundamentada nas avaliações das atividades e programas da Casa da Ciência, que envolvem grupos de pesquisadores, professores e alunos de escolas públicas e particulares de Ribeirão Preto e região.

O folhetim propõe um novo formato de divulgação científica em sete anos de existência da Casa da Ciência e três anos de consolidação do MuLEC. Juntamente com o "Jornal das Ciências" (publicação trimestral com 18 edições) e o site "Portal das Ciências", compõe a construção da memória escrita dos projetos desenvolvidos. Em formato pequeno (uma folha A4, dobrada como um folder), apropriado à leitura rápida, caracterizam-se pela diversidade de conceitos temáticos, trazendo assuntos científicos atuais escritos por pesquisadores, proporcionando a revisão de temas e o entendimento dos conceitos básicos, geralmente trabalhados superficialmente nos livros didáticos.

O presente trabalho procurou avaliar o uso de um texto de divulgação científica, o folhetim, desenvolvido pela Casa da Ciência do Hemocentro de Ribeirão Preto, com apoio de pesquisadores, no processo de aprendizagem de alunos, verificando a compreensão e a articulação de conceitos de Ecologia a partir de registros de aula e respostas a questionários.

\section{Metodologia}

\section{Fundamentação teórica}

Segundo Odum (1977), é interessante reconhecer quatro constituintes estruturais que compõem os ecossistemas: substâncias abióticas, elementos básicos e compostos do meio; produtores, os organismos autotróficos, sobretudo as plantas verdes; os grandes consumidores ou macroconsumidores, organismos heterotróficos, especialmente animais, que ingerem outros organismos ou determinada matéria orgânica; os decompositores ou microconsumidores, organismos heterótrofos, sobretudo as bactérias e fungos, que decompõem os componentes complexos do protoplasma morto, absorvem alguns dos produtos da decomposição e liberam substâncias simples utilizáveis pelos produtores. Todos os ecossistemas, como um lago ou uma floresta, apresentam estes componentes.

Para entender o funcionamento de um ecossistema, é necessário conhecer e articular os diferentes conceitos e fenômenos, entendendo suas relações. Mas, como enfatizam Martins e Guimarães (2002, p. 9):

Em um grande número de livros, a natureza e seus fenômenos são apresentados por partes, dificultando a compreensão da natureza como 
um todo. $\mathrm{O}$ ar, a água, o solo e os seres vivos são apresentados em capítulos distintos, não estabelecendo as inter-relações existentes entre seres vivos e entre esses e o meio.

Muitos professores, no entanto, afirmam utilizar livros didáticos como sendo a principal ou única fonte de textos utilizados em suas aulas (GAMBARINI e BASTOS, 2006) e, para os alunos, é a única fonte para suas pesquisas e estudo (SANTOS et al., 2007).

Desta forma, o conhecimento apresentado de maneira fragmentada ao aluno favorece somente a aprendizagem de fatos e terminologias, dificultando a articulação entre os conceitos e a percepção da interdependência entre os diferentes componentes, presentes em um ambiente, pouco desenvolvendo outras habilidades cognitivas, como compreensão, interpretação, análise e síntese, quando o estudo é apoiado em uma atividade de leitura superficial, não colocando o aluno em uma atitude ativa diante do texto em uma situação de sujeito-agente (AZAMBUJA e SOUZA, 1995).

O ensino de Ciências, de forma geral, e o de Ecologia, especificamente, devem ter como objetivo o desenvolvimento de habilidades intelectuais mais complexas do que a simples memorização de conceitos. É necessário desenvolver, no aluno, outras capacidades como: observar, traduzir, analisar, formular hipóteses, sintetizar, julgar, entre outras -, para se perceber as inter-relações entre os componentes de um ecossistema. Para isso, o professor deve levar em consideração que a aprendizagem destas habilidades supõe atividades diferenciadas (VIELLA, 2006) e, nesse caso, os objetivos educacionais de Bloom et al. (1973) devem ser considerados no planejamento das práticas pedagógicas.

A taxonomia dos objetivos educacionais de Bloom et al. (1973) é uma estrutura de organização hierárquica de objetivos educacionais, que procura definir, de forma clara, precisa e verificável, o objetivo a ser atingido ao final de uma ação educacional. Para tal, os autores dividiram as possibilidades de aprendizagem em três grandes domínios: o cognitivo, o afetivo e o psicomotor. Cada um desses domínios tem diversos níveis de profundidade de aprendizado. Por isso, essa classificação é denominada taxonomia, na qual cada nível é mais complexo e mais específico do que o anterior.

Neste estudo, trabalhamos somente com o domínio cognitivo, que considera as seguintes categorias: conhecimento (memorização de fatos específicos, terminologias e conceitos), compreensão (imprime significado, traduz, interpreta problemas, instruções), aplicação (utiliza o aprendizado em novas situações), análise (de elementos, de relações e de princípios de organização), síntese (reconhecer as diferentes partes que formam o todo), e avaliação (exige a compreensão, análise e, antes de julgar, considerar esses elementos para julgar).

O uso de textos de divulgação, segundo Salém e Kawamura (1996), pode contribuir para enriquecer a aula "trazendo novas questões, abrindo a visão de ciência e de mundo do aluno e professor, criando novas metodologias e recursos de ensino, localizando o conteúdo ensinado em contexto mais abrangente, motivando e mesmo aprofundando determinados assuntos". Portanto, o uso de textos de divulgação científica, como os desenvolvidos no projeto "Folhetins: Material de Divulgação Científica do MuLEC", da Casa da Ciência, não se destina a substituir o livro, mas complementá-lo, trazendo uma nova abordagem de temas e conceitos, mostrando suas articulações, além de trazer conceitos atuais não presentes no livrotexto. 
Contudo, somente o texto não é suficiente para garantir uma aprendizagem significativa. O papel do professor no processo é fundamental, atuando como um estimulador do pensamento e de atitudes criativas nos alunos, proporcionando condições para que a sala de aula seja um espaço de novas ideias, e não um local onde ocorre a simples repetição de fatos já conhecidos (WECHSLER, 2006). É preciso que o texto seja utilizado de maneira adequada, com uma preparação prévia do aluno para a leitura, motivando-o e despertando nele o interesse e a curiosidade para a leitura. Como apontam Seneciato e Cavassan (2004, p. 133):

As aulas de Ciências e Biologia desenvolvidas em ambientes naturais têm sido apontadas como uma metodologia eficaz tanto por envolverem e motivarem crianças e jovens nas atividades educativas, quanto por constituírem um instrumento de superação da fragmentação do conhecimento.

\section{Método}

A pesquisa foi realizada com 33 alunos do Ensino Básico, a maioria do Ensino Fundamental, das redes pública e particular das cidades de Ribeirão Preto, Luis Antonio e Pradópolis, no interior de São Paulo, que participavam do programa "Sextas da Ciência", desenvolvido pela Casa da Ciência, no ano de 2007 (Tabela I).

Tabela I. Caracterização dos alunos participantes.

\begin{tabular}{|c|c|c|c|}
\hline Cidade & Rede de ensino & Série & Número de alunos \\
\hline Luiz Antonio & Pública & $8^{\mathrm{a}}$ E.F. & 17 \\
\hline \multirow[t]{3}{*}{ Pradópolis } & Pública & $6^{\mathrm{a}}$ E.F. & 2 \\
\hline & Pública & $7^{\mathrm{a}}$ E.F. & 3 \\
\hline & Pública & $8^{\mathrm{a}}$ E.F. & 1 \\
\hline \multirow[t]{7}{*}{ Ribeirão Preto } & Pública & $6^{\mathrm{a}}$ E.F. & 1 \\
\hline & Pública & $7^{a}$ E.F. & 1 \\
\hline & Pública & $2^{\circ} \mathrm{E} . \mathrm{M}$. & 1 \\
\hline & Pública & $3^{\circ}$ E.M. & 1 \\
\hline & Particular & $6^{a}$ E.F. & 3 \\
\hline & Particular & $7^{a}$ E.F. & 1 \\
\hline & Particular & $8^{\mathrm{a}}$ E.F. & 2 \\
\hline Total & & & 33 \\
\hline
\end{tabular}

A maioria frequentava a $8^{a}$ série do Ensino Fundamental em escolas públicas do município de Luis Antonio, a sessenta km de Ribeirão Preto; vinham acompanhados por uma professora de Ciências - que já havia participado de projetos anteriores da Casa da Ciência com apoio da Secretaria de Educação da cidade de Luis Antonio, que cedeu transporte aos alunos.

A prática pedagógica, dividida em duas etapas, foi baseada no trabalho de Azambuja e Souza (1995), que propõem, como técnica de ensino, o estudo de texto. Na primeira, foi 
realizada uma atividade de campo para observação e coleta de materiais no lago e mata ciliar do campus da USP/Ribeirão Preto, com intuito de preparar o aluno para a segunda etapa, que ocorreu no Hemocentro e consistiu na leitura, estudo e discussão de um folhetim produzido pela Casa da Ciência. Toda a atividade foi registrada em vídeo.

O texto de divulgação "Lago e floresta tão diferentes, mas muito semelhantes", trabalhado com os alunos, aborda as semelhanças entre os ecossistemas aquático e terrestre, no caso, um lago e a mata ciliar. O objetivo deste folhetim é discutir temas básicos de Ecologia ${ }^{5}$, trabalhados de maneira articulada, com foco no funcionamento dos diferentes ambientes, para que o leitor perceba os componentes em comum e a dinâmica de ambos.

Para averiguação dos conhecimentos prévios dos alunos e avaliação da aprendizagem e articulação de conceitos de Ecologia, foram aplicados três questionários (Anexo I): um diagnóstico, antes da primeira etapa da prática pedagógica; um intermediário, após a leitura do folhetim, e um final, para verificar a aprendizagem após a intervenção dos professores, biólogos da Casa da Ciência e autores deste trabalho. O papel dos professores durante todo o processo foi o de mediador entre os alunos e o conhecimento, sendo que, após a leitura do texto, promoveram um debate para discutir os conceitos apresentados.

Para se avaliar o grau de compreensão e articulação de $\operatorname{conceitos}^{6}$, ou seja, capacidades cognitivas diversas, pelos alunos, assim como a intervenção dos professores após leitura do folhetim, as respostas aos questionários foram analisadas, de acordo com os objetivos cognitivos propostos por Bloom et al. (1973), procurando-se avaliar, nos alunos, capacidades cognitivas mais complexas, em relação aos seguintes temas de Ecologia:

1) Conhecimentos de conceitos e terminologias sobre ecossistema, fatores bióticos e abióticos, cadeia alimentar, produtores, decompositores e seres heterótrofos.

2) Compreensão ou capacidade de explicar as relações entre os conceitos e fenômenos, ou seja, a relação entre fatores bióticos e abióticos, decompositores e ciclagem da matéria e produtores com a fotossíntese, cadeia alimentar e fluxo de energia.

3) Aplicação, análise e síntese, isto é, a capacidade de articulação entre os diversos conceitos, percebendo semelhanças no funcionamento de diferentes ecossistemas (lago e mata ciliar) e reconhecendo componentes em comum, como produtores, consumidores e decompositores, além das relações entre si e com os fatores abióticos.

Além do registro escrito, foi realizada análise do vídeo para evidenciar momentos da construção e articulação dos conceitos pelos alunos, durante intervenção dos professores. Os dados foram analisados qualitativa e quantitativamente.

\footnotetext{
${ }^{5}$ Atualmente, a Ecologia tem sido foco de assuntos abordados em diferentes mídias (revistas, jornais e televisão), sobretudo os temas relacionados a problemas ambientais, como o aquecimento global. Entretanto, a palavra ecologia, muitas vezes, é usada para identificar um movimento social com características de um movimento de defesa do ambiente (ACOT, 1990). Porém, pouco se fala - nas mídias mais populares - da Ecologia como uma área científica, e pouco se abordam conceitos e fenômenos típicos desta ciência. Contudo, não se nega a importância destes textos para a conscientização da população.

${ }^{6}$ A escola, muitas vezes, tende a valorizar, especialmente, o conhecimento de definições, fatos e terminologias (VIELLA, 2006) em detrimento de outros aspectos cognitivos, como a capacidade de relacionar, aplicar e analisar fenômenos, ou seja, de outras competências possíveis.
} 


\section{Análise e discussão dos resultados}

A Ecologia é uma ciência que estuda as interações entre os seres vivos e com o ambiente que os cerca. Para entender o funcionamento de diferentes ecossistemas, por exemplo, é necessário não apenas conhecer conceitos - como produtores, consumidores, decompositores, cadeia alimentar -, ou seja, fatos e terminologias, mas é preciso que o aluno os compreenda e os articule, identificando componentes em comum entre os diferentes ecossistemas, percebendo as interdependências e inter-relações entre os componentes físico-químicos e biológicos dos ambientes. Os dados foram analisados com o intuito de se verificar se os alunos foram capazes de realizar articulações com os conceitos aprendidos, indo além do nível de conhecimento, de acordo com Bloom et al. (1973).

As respostas dos alunos foram analisadas individualmente na tentativa de se averiguar se o processo pedagógico utilizado mostrou-se eficiente na aprendizagem (Figura 1).

Quando analisado o desempenho dos alunos em relação à aquisição e conhecimentos de fatos e terminologias, no questionário diagnóstico, a maioria desconhecia os conceitos básicos de produtores e decompositores, fatores bióticos, abióticos e cadeia alimentar (Figura 1A).

Este fato pode ser observado nas respostas dos alunos em relação aos conceitos de produtores, decompositores, fatores bióticos e abióticos e cadeia alimentar:

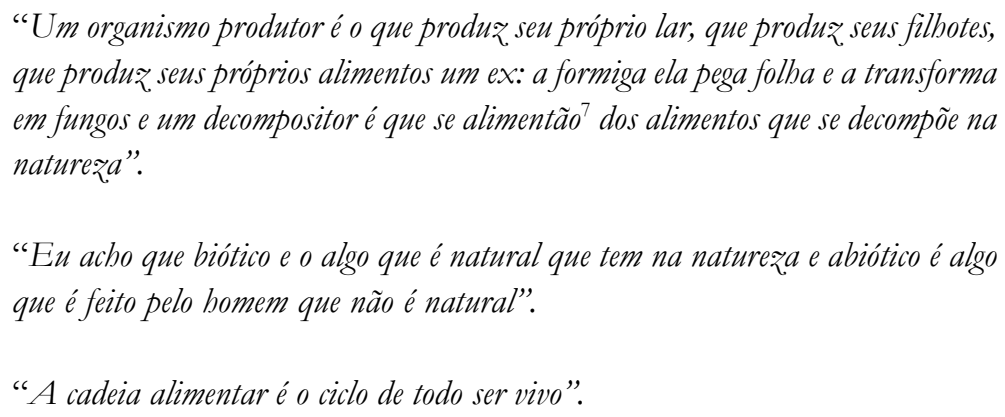

Este quadro se inverte ao final do processo, quando a maioria passou a conhecê-los. Inicialmente, dois alunos conheciam os conceitos corretos e 16 desconheciam. Após a aplicação dos folhetins, este número aumentou para 14 e, com a finalização do processo, depois da intervenção dos professores, vinte alunos passaram a conhecer tais conceitos (Figura 1A). Isso pode ser verificado na resposta de um aluno (A1) antes e após a leitura do folhetim e posterior à discussão, conduzida pelos professores, em relação ao conceito de fatores bióticos a abióticos.

Antes da leitura e discussão do folhetim:

A1: "Bióticos - seres vivos (que nascem, reproduzem-se e morrem). Abióticos ambiente (solo, atmosfera, etc.)".

\footnotetext{
${ }^{7} \mathrm{Na}$ transcrição, mantivemos a íntegra das respostas, inclusive com erros gramaticais e de estrutura. 
Perticarrari, A. et al.
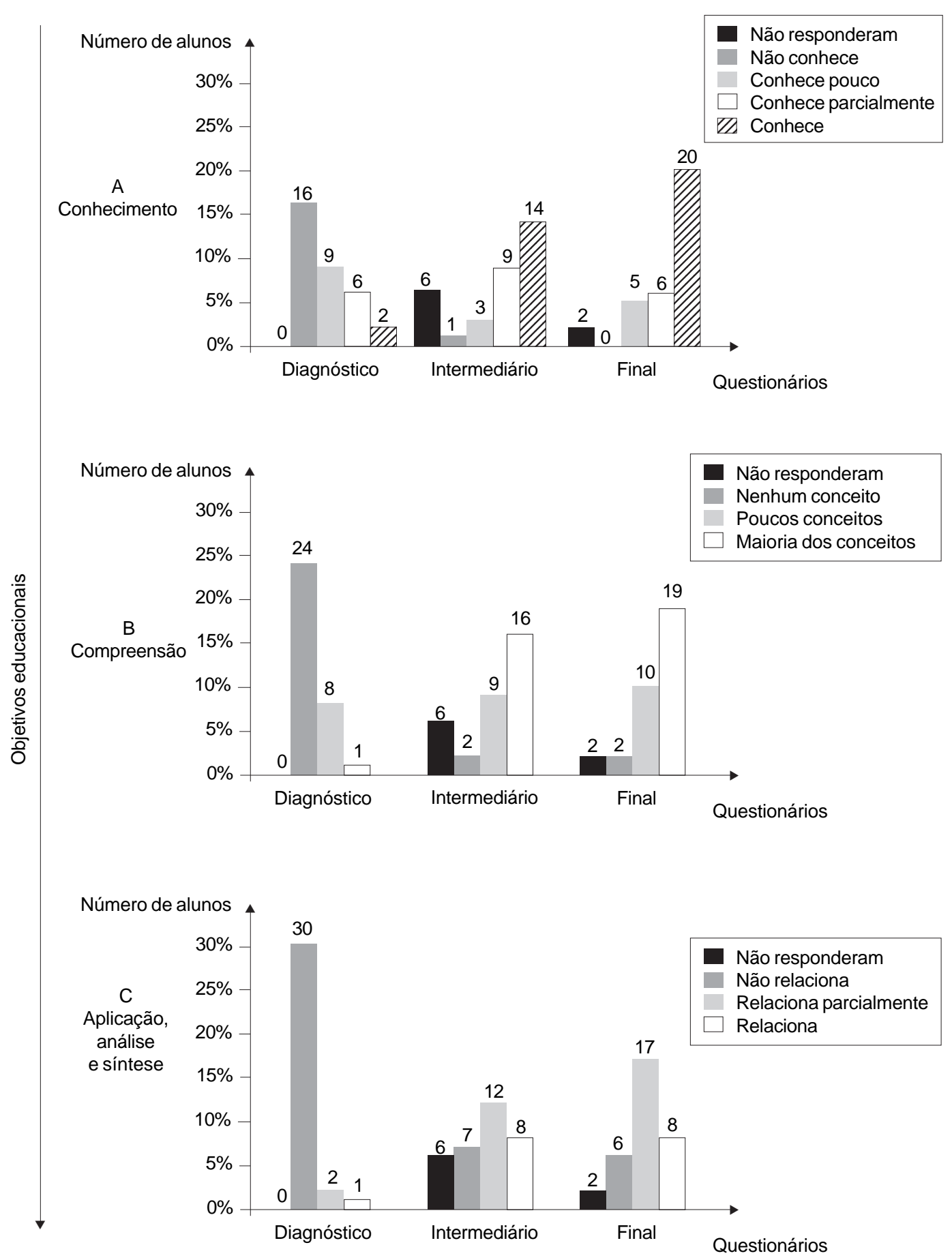

Figura 1. Respostas dos alunos aos questionários de acordo com os níveis cognitivos propostos por Bloom et al. (1973). (A) Avaliação do conhecimento de conceitos, (B) da compreensão de conceitos e (C) da articulação e relação entre os conceitos de ecologia pelos alunos. 
Após a leitura e discussão do folhetim:

A1: "Fatores bióticos são os seres que estão no ambiente por um propósito, "buscar energia para se manterem", esses seres, são os seres vivos que nascem, crescem e reproduzem-se. Fatores abióticos são o próprio "meio ambiente", fatores físicoquímicos como água, ar, solo, temperatura, pressão, etc. Esses fatores se relacionam no ecossistema, sem um ambiente não se pode ter vida, os fatores abióticos influenciam nos fatores bióticos. O peixe e a água é um exemplo dessa relação".

No segundo nível dos objetivos cognitivos - a compreensão dos conceitos -, a análise mostra que, no início, os alunos não os relacionavam com nenhum fenômeno (Figura 1B). Como, por exemplo, o fato de não associarem organismos produtores à cadeia alimentar $\mathrm{e}$ fotossíntese, além do papel do Sol nesses processos:

"A cadeia alimentar é onde um animal se alimenta do outro. Um tubarão se alimenta de pequenos peixes".

"O papel é aquecer nos e ajudar o meio ambiente".

"Sem o sol as plantas morreriam sem elas muitos animais morreriam matando toda a vida do planeta".

Como visto acima, os produtores não aparecem como componente da cadeia alimentar, e as plantas, quando citadas, não aparecem associadas ao processo de fotossíntese. Isso foi verificado na maioria das respostas.

Após atividade com o folhetim e intervenção do professor, percebe-se claramente que a maioria dos alunos passa a relacionar o conceito de produtor com os fenômenos apresentados acima, evidenciando a aprendizagem de um conceito mais amplo.

"Pois é a fonte de energia (o Sol - grifo nosso) de onde os produtores a partir da fotossintese produzem matéria orgânica. Assim é a "fonte de energia" de toda a cadeia alimentar".

"Porque todos nós precisamos do sol e energia. Um exemplo os produtores precisam do sol para fazer a fotossintese e depois a cadeia alimentar continua".

Portanto, como observado no gráfico, inicialmente apenas um aluno associava os conceitos aos fenômenos - que era, por exemplo, relacionar os conceitos de produtores e cadeia alimentar com a fotossíntese - e 24 desconheciam ou estavam bastante aquém do esperado (Figura 1B). O número aumentou para 16 após a aplicação dos folhetins e, depois da intervenção do professor, 19 alunos passaram a dominar os conceitos, compreendendo-os de maneira mais profunda.

Em relação às articulações de conceitos, em que capacidades cognitivas mais complexas foram trabalhadas (aplicação, análise e síntese), percebe-se que o aumento não foi tão 
Perticarrari, A. et al.

pronunciado quanto os encontrados nos níveis iniciais, ou seja, o conhecimento de terminologias e a compreensão (Figura 1C). No entanto, muitos alunos apresentaram capacidade parcial de relacionar certos conceitos, percebendo alguns componentes em comum entre os dois ecossistemas (lago e mata ciliar), o que não ocorria antes da atividade pedagógica.

Percepção dos componentes em comum entre os ecossistemas aquático e terrestre, antes da leitura e discussão do folhetim:

A2: "É um tipo de natureza. Eu acho que a floresta e o lago é um ecossistema sim como na floresta as árvores e no lago os peixes".

A3: "É um sistema de conjunto da natureza, sim também".

E após leitura e discussão do folhetim:

A2: "Eles apresentam os mesmos componentes: produtores, consumidores microconsumidores".

A3: "Os dois são constituidos por espécies convivendo e interagindo. Elas apresentam uma organiżação baseada primariamente na obtenção de energia".

Inicialmente, observou-se que a maioria dos alunos (trinta) não conseguiu articular todos os conceitos, não alcançando níveis mais complexos que exigiam aplicação, análise e síntese (Figura 1C). Este número, durante o processo, diminuiu significativamente, chegando a somente seis alunos no último questionário aplicado (Figura 1C). Ao se verificar os alunos que conseguiram superar situações novas, identificar a ideia principal abordada (neste caso, a dinâmica dos ecossistemas aquáticos e terrestres), chegando à formulação de um modelo, ou estrutura que antes não existia claramente em seus esquemas cognitivos, constata-se um aumento (de apenas um aluno para oito, tanto após a leitura do folhetim quanto depois da intervenção do professor), mas não tão expressivo quanto ao comparado àqueles com capacidade parcial de relacionar os conceitos (inicialmente, dois alunos no questionário diagnóstico, passando a 12 no intermediário, e 17 ao final. Figura 1C).

Estes resultados mostram que muitos alunos conseguiram articular vários conceitos, porém, a maioria não alcançou todos os objetivos do folhetim. Contudo, dois alunos atingiram o esperado, articulando, de maneira bastante profunda, os conceitos trabalhados:

Antes da leitura e discussão do folhetim, os alunos não articulavam conceitos (aluno 4):

A4: "O meio ambiente em geral (florestas animais etc). Água, animais, organismos, pedras...” (resposta à pergunta do questionário diagnóstico sobre quais componentes do lago e mata ciliar permitem reconhecê-los como ecossistemas).

Após a leitura do folhetim, verifica-se que o aluno passa a discutir de maneira mais profunda os conceitos: 
A4: "No ambiente terrestre os organismos produtores são as grandes árvores", $e$ no lago são representados pelas algas unicelulares (que tem uma só célula). Ambos desempenham a mesma função ecológica, transforma a energia luminosa em matéria orgânica (glicose) pelo processo de fotossintese. OBS: Os microconsumidores também são de extrema importância para o funcionamento do ecossistema”.

A4: "Se olharmos para um ambiente aquático e uma floresta veremos que eles são constituidos por várias espécies convivendo e interagindo. E estas, apresentam uma organização baseada primariamente na obtenção de energia”.

Antes da leitura e discussão do folhetim, observa-se o mesmo para o aluno 5:

A5: "A interrelação observada entre as variedades de seres vivos existentes nos dois ambientes, a própria presença de seres vivos de espécies diferentes vivendo e interagindo com o meio ambiente".

Após a leitura do folhetim, o aluno passa a discutir os fenômenos de forma mais clara:

A5: "Constituido de vários seres vivos de espécies diferentes que interagem entre si e o meio ambiente em que vivem, nos dois ambientes formam uma interação de ecossistemas, onde temos teias e relações e cadeias alimentares de produção, consumo e "reciclagem" da matéria".

Estes alunos, contudo, já apresentavam conhecimentos prévios de Ecologia, evidenciados pelo questionário diagnóstico. Isso demonstra que, indiferentemente do nível de conhecimento prévio apresentado pelo aluno, o folhetim, juntamente com a intervenção do professor, conseguiu acrescentar e provocar articulações de novos conceitos. Percebe-se claramente que quanto maior o grau de conhecimentos sobre o tema apresentado inicialmente pelo aluno, articulações mais profundas são alcançadas. Confirma-se então que, durante o processo cognitivo, etapas (conhecimento de fatos, compreensão e articulação de conceitos) não podem ser puladas, como evidenciado acima. É necessário passar por cada uma delas, visando, ao final do processo, a construção de uma malha de conceitos, e não apresentá-los de forma fragmentada, como normalmente são apresentados.

Numa análise quantitativa, percebe-se que houve um crescimento cognitivo geral do grupo de alunos na aprendizagem dos temas de Ecologia, trabalhados na prática pedagógica de forma geral e no texto em particular. Nesta abordagem, as respostas foram classificadas em três categorias apresentadas na Tabela 2 .

\footnotetext{
${ }^{8} \mathrm{Na}$ transcrição, mantivemos a íntegra das respostas. Porém, durante as aulas foi mencionado que, no ambiente terrestre, além das grandes árvores, outros organismos podem atuar como produtores, como: briófitas, pteridófitas, plantas herbáceas, líquens, entre outros.
} 
Perticarrari, A. et al.

Tabela 2. Porcentagem de respostas dos alunos que estavam "acima, próxima e distante do esperado" de acordo com o gabarito dos questionários.

\begin{tabular}{lccc}
\hline & \multicolumn{3}{c}{ Porcentagem de respostas (\%) } \\
\cline { 2 - 4 } & Questionário diagnóstico & Questionário intermediário & Questionário final \\
\hline Distante do esperado & 77,6 & 15,4 & 14,9 \\
Próxima do esperado & 21,2 & 67,3 & 76,1 \\
Acima do esperado & 1,2 & 17,3 & 9,0 \\
Total & $\mathbf{1 0 0}$ & $\mathbf{1 0 0}$ & $\mathbf{1 0 0}$ \\
\hline
\end{tabular}

A classificação de uma resposta como "distante do esperado", não significava que estivesse errada, mas que apenas não era prevista ou se mostrava muito diferente em relação ao gabarito previsto. Quanto à classificação como "acima do esperado", compreendem-se as respostas que superaram o gabarito quanto aos conceitos trabalhados, normalmente apresentando níveis mais complexos de articulações, que não eram exigidos na questão.

Esta análise corrobora os resultados apresentados anteriormente, evidenciando que o grupo como um todo se beneficiou com o processo pedagógico, sobretudo logo após a leitura do texto (questionário intermediário).

No entanto, ao se analisar o vídeo da aula, verifica-se que a intervenção do professor foi importante na articulação dos conceitos trabalhados no texto. A discussão, quando estruturada de maneira a proporcionar a participação de todos - orientada pelo professor, que desafia o aluno e leva-o a construírem, juntos, um conceito -, cria condições para a aprendizagem.

Portanto, a aula não foi expositiva, pelo contrário, foi dialógica. A todo momento, os alunos eram desafiados a responderem perguntas e a relacionarem os conceitos aprendidos com o estudo do texto, como demonstrado na transcrição de alguns trechos da aula:

$[\cdots]$

Prof.: "Então o ambiente terrestre tem um produtor e tem um consumidor?"

Alunos: "Sim, tem".

Prof.: "E o ambiente aquático?"

Aluno: "Também".

Prof.: "E quais são as semelhanças e diferenças entre ambiente aquático e terrestre?" Alunos (vários ao mesmo tempo): "Tem organismo produtor, consumidor, transforma a energia luminosa em matéria orgânica’".

$[\cdots]$

Prof.: "Então todo ambiente aquático tem cadeia alimentar?"

Alunos: "Sim".

\footnotetext{
${ }^{9} \mathrm{Na}$ transcrição, mantivemos a íntegra das respostas dos alunos. Durante o processo, não exatamente neste momento, foi discutido o papel dos produtores na conversão de energia luminosa em energia química, e não em matéria orgânica.
} 
A construção de conceitos em Ecologia ...

Prof.: "Mas a floresta não é um ecossistema e o lago outro?"

Aluno: "Sim, eles são constituidos por várias espécies que estão convivendo e interagindo".

$[\ldots]$

Prof.: "Qual a relação das árvores do ambiente terrestre com as algas do ambiente aquático?"

Aluna: "Transformar energia luminosa em matéria orgânica".

Prof.: "E ela vai usar essa matéria orgânica para que?"

Aluna: "Para se alimentar?"

Prof.: "E consequentemente serve de alimento para alguém? Então qual a importância de tudo isso?"

Alunos: "Equilíbrio do ambiente, cadeia alimentar".

$[\cdots]$

Prof.: "Conseguiram perceber as semelhanças entre um lago e uma floresta? São muito diferentes, você vê um lago e só vê água, na floresta um monte de coisa. Mas, funcionam da mesma maneira?"

Alunos: "Funcionam"

Prof.: "Então, um rio é um ecossistema?"

Alunos: "É",

O papel do professor como mediador foi importante, ele não apenas apresentou conceitos, mas ajudou os alunos a perceberem os componentes comuns aos dois ecossistemas, perceberem as semelhanças de funcionamento, construindo, juntos, os conceitos.

\section{Considerações finais}

Os resultados demonstram que, apesar dos conteúdos estarem nos livros didáticos ou em um texto de divulgação científica, a relação professor-aluno é fundamental para os alunos alcançarem os objetivos mais complexos, ou seja, para fazerem articulações mais profundas entre os diferentes conceitos (DARÉ, CARVALHO e BARBIERI, 1998). Essa relação não pode ser de cima para baixo, com uma atitude passiva do aluno, deve ser horizontal, isto é, dialógica, na qual ambos possam discutir e refletir sobre os temas abordados (LOPES, 1995). Segundo Oliveira e Carvalho (2005), "quando o aluno argumenta sobre um conceito científico, ele está processando cognitivamente toda a sua compreensão da atividade". Portanto é fundamental que o professor estimule o aluno a verbalizar, sendo este um instrumento cognitivo importante para a compreensão de conceitos (WARWICH, LINFIELD e STEPHENSON, 1999). Além disso, é imprescindível, também, estimular o aluno a escrever, pois seu uso é fundamental para retenção de conhecimentos, ou seja, a escrita, como instrumento cognitivo, tende a ser uma ferramenta importante para organizar e consolidar ideias em conhecimento mais coerente e bem estruturado (OLIVEIRA e CARVALHO, 2005). Mas como afirmam estes mesmos autores "para a escrita ser efetiva, os estudantes já devem destacar certo conhecimento 
Perticarrari, A. et al.

básico, interagir com seus semelhantes para compartilhar, clarificar e distribuir este conhecimento. Só então, a escrita mostra um efeito positivo na aprendizagem da Ciência" (p. 349).

Outro fato observado, neste estudo, é que os alunos que apresentavam conhecimentos prévios de temas relacionados com a Ecologia foram aqueles que conseguiram estabelecer as relações mais profundas. Isso demonstra que o uso do texto, no caso o folhetim, foi uma ferramenta importante para esses alunos realizarem tais articulações, atribuindo um significado aos conceitos prévios apresentados por eles.

Com os resultados obtidos, pode-se afirmar que o uso de um texto adequadamente planejado, com uma preparação prévia para leitura (esse foi o objetivo da aula de campo realizada com os alunos no lago e mata ciliar do campus da USP de Ribeirão Preto) e associado ao papel do professor, interferindo no processo cognitivo, possibilita que o aluno supere o nível de conhecimento de definições e fatos, alcançando níveis cognitivos mais complexos, importantes para a aprendizagem significativa de forma geral e para aprendizagem de temas relacionados à ecologia de forma específica.

As condições de trabalho e aplicação também podem ter interferido nos resultados obtidos, visto que o tempo utilizado neste estudo (somente dois encontros) e o grupo de alunos avaliado (grupo bastante heterogêneo em idade, série, escola e cidade) podem ter levado a desvios do resultado esperado, sendo que alguns alunos não chegaram a perceber as semelhanças entre os diferentes ambientes. Alguns cursavam a $6^{a}$ série $\left(7^{\circ}\right.$ ano pela nomenclatura atual), em que os primeiros conceitos em ecologia estão sendo vistos, sendo, neste caso, o primeiro contato com o tema. Provavelmente, em uma sala de aula, o professor, com um tempo maior e constante de trabalho e com um planejamento adequado, pode alcançar resultados mais significativos.

No entanto, este trabalho mostrou que o folhetim é uma forma diferente de apresentar vários temas de maneira inovadora, articulando os conceitos que, muitas vezes, são trabalhados de forma fragmentada pelo livro didático. $\mathrm{O}$ uso desse texto de divulgação científica no processo de aprendizagem dos alunos foi eficiente, com resultados que merecem ser divulgados, validando, por sua vez, o projeto Folhetins desenvolvido pela Casa da Ciência.

\section{Agradecimentos}

Ao Fundo de Cultura e Extensão da Universidade de São Paulo - USP, pelo apoio financeiro ao projeto Folhetins; à FAPESP, pelo apoio ao projeto educacional do Centro de Terapia Celular-CTC/FMRP USP; ao Hemocentro de Ribeirão Preto; e a Fernanda Udinal e Alessandra Almeida, pela revisão final. 
A construção de conceitos em Ecologia ...

\section{Referências}

ACOT , P. História da Ecologia. Rio de Janeiro: Campus, 1990.

AZAMBUJA, J. Q.; SOUZA, M. L. R. O estudo de texto como técnica de ensino. In: VEIGA, I. P. A. (Org.). Técnicas de ensino: por que não? Campinas: Papirus, 1995. p. $49-65$.

BLOOM, B.; KRATHWOHL, D. R.; DAVID, R.; MASIA, B. B. Taxionomia dos objetivos educacionais: domínio cognitivo. Porto Alegre: Globo, 1973.

CARVALHO, A. M. P.; GIL-PÉREZ, D. Formação de professores de ciências: tendências e inovações. São Paulo: Cortez, 1993.

DARÉ, G. L. R.; CARVALHO, C. P.; BARBIERI, M. R. Pesquisando o que se ensina: uma metodologia para o aprimoramento contínuo da educação. Pediatria, São Paulo, v. 20, n. 4, p. 292-300, 1998.

DEMO, P. Pesquisa participante: mito e realidade. SENAC/DN, Rio de Janeiro, n. 11, 1984.

Educar pela pesquisa. 3. ed. Campinas: Autores Associados, 1996.

DRIVER, R. Students' conceptions and the learning of sciences. International Journal on Science Education, London, v. 11, n. 5, p. 481-490, 1989.

GAMBARINI, C.; BASTOS, F. A utilização do texto escrito por professores e alunos nas aulas de Ciências. In: NARDI, R.; ALMEIDA, M. J. P. M. (Orgs.). Analogias, leituras e modelos no ensino da ciência: a sala de aula em estudo. São Paulo: Escrituras, 2006. p. $93-115$.

LOPES, A. O. Aula expositiva: superando o tradicional. In: VEIGA, I. P. A. (Org.). Técnicas de ensino: por que não? Campinas: Papirus, 1995. p. 35-48.

MARTINS, E. F.; GUIMARÃES, G. M. A. As concepções de natureza nos livros didáticos de ciências. Ensaio, Belo Horizonte, v. 4, n. 2, p. 1-14, 2002.

MARTINS, I.; NASCIMENTO, T. G.; ABREU, T. B. Clonagem na sala de aula: um exemplo do uso didático de um texto de divulgação científica. Investigações em ensino de ciências, Porto Alegre v. 9, n. 1, p. 95-111, 2004. Disponível em: < http:// www.if.ufrgs.br/ienci>. Acesso em: 11 abr. 2008.

ODUM, E. P. Ecologia. 3. ed. São Paulo: Pioneira, 1977.

OLIVEIRA, M. K. Vygotsky - aprendizado e desenvolvimento: um processo sóciohistórico. São Paulo: Scipione, 1993.

OLIVEIRA, C. M. A.; CARVALHO, A. M. P. Escrevendo em aulas de ciências. Ciência e Educação, Bauru, v. 11, n. 3, p. 347-366, 2005.

PERTICARRARI, A.; BARBIERI, M. R.; GODOI, V. M.; COVAS, D. T.; AUGUSTO, A. S. Pós-graduandos e alunos do ensino básico em um trabalho de difusão científica.

Experiências em ensino de ciências, Porto Alegre, v. 2, n. 1, p. 79-89, 2007. Disponível em: <http://www.if.ufrgs.br/eenci>. Acesso em: 10 mar. 2008. 
Perticarrari, A. et al.

PIAGET, J. O desenvolvimento do pensamento: equilibração de estruturas cognitivas. Lisboa: Dom Quixote, 1977.

SALÉM, S.; KAWAMURA, M. R. O texto de divulgação e o texto didático: conhecimentos diferentes? In: ENCONTRO DE PESQUISADORES EM ENSINO DE FÍSICA, 5., 1996, Belo Horizonte. Anais... Belo Horizonte: SBF, 1996. 1 cd-rom.

SANTOS, J. C.; ALVES, L. F.; CORRÊA, J. J.; SILVA, E. R. L. Análise comparativa do conteúdo Filo Mollusca em livro didático e apostilas do ensino médio de Cascavel, Paraná. Ciência e Educação, Bauru, v. 13, n. 3, p. 311-322, 2007.

SENICIATO, T.; CAVASSAN, O. Aulas de campo em ambientes naturais e aprendizagem em ciências: um estudo com alunos do ensino fundamental. Ciência e Educação, Bauru, v. 10, n. 1, p. 133-147, 2004.

VIELLA, M. A. L. Das intenções aos objetivos educacionais. In: CASTANHO, S.;

CASTANHO, M. E. (Orgs.). Temas e textos em metodologia do ensino superior. Campinas: Papirus, 2006. p. 113-123.

WARWICK, P.; LINFIELD, R. S.; STEPHENSON, P. A. Comparison of primary school pupils' ability to express procedural understanding in science through speech and writing. International Journal of Science Education, London, v. 21, n. 8, p. 823-838, 1999.

WECHSLER, S. M. A educação criativa: possibilidade para descobertas. In: CASTANHO, S.; CASTANHO, M. E. (Orgs.). Temas e textos em metodologia do ensino superior. Campinas: Papirus, 2006. p. 165-170. 
A construção de conceitos em Ecologia ...

ANEXO I

\section{Questionário diagnóstico:}

\section{Casa da Ciência - Hemocentro de Ribeirão Preto}

Programa Adote um Cientista 2007

Sexta da Ciência

Nome:

Data de nascimento:

Escola: Série:

1) O que você entende por ecologia?

2) Para você o que é um ecossistema? Uma floresta é um ecossistema? E um lago? Se você acha que sim, que fatores existentes em um lago e em uma floresta fazem você reconhecê-los como ecossistemas?

3) O que você entende por fatores bióticos e abióticos?

4) Explique, com suas próprias palavras, o que você entende por cadeia alimentar? Dê um exemplo.

5) Qual o papel do Sol para a vida no planeta?

6) Você saberia dizer o que é um organismo produtor? E um decompositor?

Questionário intermediário:

\section{Casa da Ciência - Hemocentro de Ribeirão Preto \\ Programa Adote um Cientista 2007 \\ Sexta da Ciência}

Nome: Data de nascimento:

Escola: Série:

1) Quem são os produtores em ambiente aquático e terrestre? Qual sua importância?

2) Organismos heterotróficos podem ser a base da cadeia alimentar?

3) Quais as semelhanças entre o ambiente aquático e uma floresta? 
Perticarrari, A. et al.

Questionário final:

Casa da Ciência - Hemocentro de Ribeirão Preto

Programa Adote um Cientista 2007

Sexta da Ciência

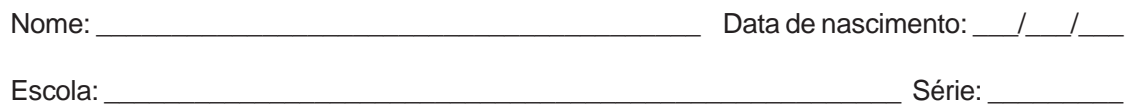

1) Quais componentes existentes em um lago e em uma mata ciliar fazem você reconhecê-los como ecossistemas? 2) O que são fatores bióticos e abióticos? De que maneira eles se relacionam? Dê exemplos de uma relação entre estes fatores.

3) Justifique a frase: "O Sol é a principal fonte energética para toda cadeia alimentar".

Artigo recebido em julho de 2009 e aceito em maio de 2010.

Ciência \&̊E Educacão, v. 16, n. 2, p. 369-386, 2010 